\title{
Linfedema primário congênito em bovinos Red Angus ${ }^{1}$
}

\author{
Juliana Targino S.A. Macêdo ${ }^{2}$, Ricardo B. de Lucena², Camila Tochetto ${ }^{3}$, \\ José Carlos Oliveira Filho², Felipe Pierezan², Luiz Francisco Irigoyen ${ }^{4}$ \\ e Claudio S.L. Barros ${ }^{4 *}$
}

\begin{abstract}
Macêdo J.T.S.A., Lucena R.B., Tochetto C., Oliveira Filho J.C., Pierezan F., Irigoyen L.F. \& Barros C.S.L. 2009. [Primary congenital lymphedema in Red Angus cattle.] Linfedema primário congênito em bovinos Red Angus. Pesquisa Veterinária Brasileira 29(9):713-718. Departamento de Patologia, Universidade Federal de Santa Maria, 97105-900 Santa Maria, RS, Brazil. E-mail: claudioslbarros@uol.com.br

Cases of congenital lymphedema were observed affecting 12 cross Red Angus calves from the central region of the state of Rio Grande do Sul, Brazil. Affected calves presented variable degrees of subcutaneous edema at birth, involving mainly the hind limbs but also other body regions. The injection of methylene blue dye in $5 \%$ solution into the interdigital space of the hind limbs of three affected calves and one normal control indicated an interruption of the lymph flow in the affected calves; this suggests a failure of the distal peripheral lymphatics to connect with the central trunks. At necropsy of three affected calves subcutaneous edema was variably observed in the hind limbs, prepuce and ventral abdomen. Edema of body cavities was not observed. In two cases there was hipoplasia of the popliteal lymph nodes associated to dilatation of lymphatic vessels. DNA tests demonstrated that all affected calves were born from cows sired by the same bull suggesting an inherited basis for the disease. Considering the small percentage of affected calves born from cows sired by the suspect bull it is probable that an autosomal recessive mode of inheritance is involved.
\end{abstract}

INDEX TERMS: Diseases of cattle, primary lymphedema, inheritable diseases.

RESUMO.- Casos de linfedema congênito foram observados acometendo 12 terneiros cruza Red Angus na região Central do Rio Grande do Sul. Os terneiros afetados apresentavam graus variáveis de edema subcutâneo ao nascimento, envolvendo principalmente os membros pélvicos, mas também outras regiões do corpo. A injeção de solução a $5 \%$ de azul de metileno no espaço interdigital dos membros pélvicos de três terneiros afetados e um controle, indicaram uma interrupção no fluxo da linfa, su-

\footnotetext{
${ }^{1}$ Recebido em 10 de abril de 2009.

Aceito para publicação em 24 de abril 2009.

Parte da Tese de Doutorado do primeiro autor.

2 Programa de Pós-Graduação em Medicina Veterinária, área de concentração em Patologia Veterinária, Centro de Ciências Rurais, Universidade Federal de Santa Maria (UFSM).

${ }^{3}$ Bolsista de Iniciação Científica (CNPq) junto ao Laboratório de Patologia Veterinária, Departamento de Patologia, UFSM, Santa Maria, RS 97105-900, Brasil.

${ }^{4}$ Depto Patologia, UFSM, 97105-900 Santa Maria, RS. Pesquisador $1 \mathrm{~A}$ do CNPq. *Autor para correspondência: claudioslbarros@uol.com.br
}

gerindo uma falha dos linfáticos periféricos distais em contactar os troncos centrais. Na necropsia de três terneiros afetados, edema subcutâneo foi observado de modo variável nos membros pélvicos, prepúcio e abdômen ventral. Não foi observado edema nas cavidades orgânicas. Em dois casos, observou-se hipoplasia dos linfonodos poplíteos associadas à dilatação dos vasos linfáticos. Testes de DNA demonstraram que todos os terneiros afetados nasceram de vacas inseminadas pelo mesmo touro, sugerindo uma base genética para a doença. Levando em consideração que uma pequena porcentagem de terneiros nasceram de vacas inseminadas pelo touro suspeito, é provável que um modo autossômico recessivo esteja envolvido na hereditariedade da doença.

TERMOS DE INDEXAÇÃO: Doenças de bovinos, linfedema primário, doenças hereditárias.

\section{INTRODUÇÃO}

O edema associado com a obstrução ou impedimento das vias linfáticas é denominado linfedema (Carmichael et al. 
1986). Linfedema primário é um distúrbio caracterizado por excessivo acúmulo de líquido no interstício, devido a defeitos no desenvolvimento dos linfáticos e dos linfonodos (Davies et al. 1979, Maxie \& Robinson 2007). Pode ocorrer como um defeito congênito isolado, isto é, afetando apenas um indivíduo (linfedema congênito simples) ou como um distúrbio familiar hereditário (Schoen 2005).

Linfedema primário hereditário é uma condição pouco freqüente, mas tem sido descrita em pessoas (Esterly 1965, Kinmonth 1965, Singh et al. 1966, Olszewski et al. 1972) bovinos das raças Ayrshire (Donald et al. 1952, Morris et al. 1954), Hereford (Schild et al. 1982, Carapeto 1984, Schild et al. 1991,1996) e Wagyu (Yamaguchi et al. 1995), cães (Luginbühl et al. 1967, Patterson et al. 1967, Davies et al.1979, Leighton \& Suter 1979, Carmichael et al. 1986) e suínos (van der Putte et al. 1978, Maxie \& Robinson 2007). Em bovinos Ayrshire (Donald et al. 1952, Morris et al. 1954), a forma de hereditariedade foi definida como autossômica recessiva e duas formas de manifestação clínica são descritas, uma forma generalizada afetando todo o corpo e uma forma mais branda que afeta cabeça, pescoço, membros e cauda (Donald et al. 1952). Em bovinos Hereford a forma de hereditariedade foi definida como autossômica dominante (Schild et al. 1991). No relato do linfedema primário congênito em terneiro Wagyu (Yamaguchi et al.1995), a lesão estava associada a displasia e aplasia de linfonodos, mas não é informado o tipo de hereditariedade.

O objetivo deste trabalho é descrever os aspectos epidemiológicos, clínicos e patológicos do linfedema congênito primário em bovinos Red Angus.

\section{MATERIAL E MÉTODOS}

Durante um ano (abril de 2008 a abril de 2009) foram realizadas visitas à propriedade onde correram os casos de linfedema para identificação e exame clínico dos bovinos afetados. Nessas oportunidades foram feitos questionários ao administrador visando completar dados epidemiológicos. Os bovinos afetados foram identificados por brincos de plástico (Quadro 1). Foi colhido sangue para hemograma e proteinograma em abril de 2008 e em abril de 2009. Na primeira oportunidade foi colhido sangue de seis bovinos (Bov. 268, 346, 349, 413545 e 948) e na segunda oportunidade de nove bovinos (Bov. 530, 907, 268, $349,413,545,948,131$ e 393).

O DNA obtido do sangue colhido de nove bovinos afetados (Bov. 131, 268, 393, 413, 349, 530, 545, 907 e 948) foi comparado com o DNA obtido do sêmen do touro usado na inseminação (Touro 1) para teste de paternidade. Para isso foram colhidos $2 \mathrm{ml}$ de sangue dos nove bovinos afetados em EDTA e sêmen (palheta) do touro. Desse material foi feita a extração e amplificação do DNA, seguida por uma reação em cadeia de polimerase (PCR), utilizando seqüências marcadas (primers) por fluoróforos e dispostos em forma de multiplex. Os locos genéticos

\section{Quadro 1. Dados dos bovinos Red Angus afetados por linfedema primário congênito

\begin{tabular}{|c|c|c|c|}
\hline Bovino & Nascimento & Sexo & Alterações observadas \\
\hline $530^{a}$ & Outubro 2006 & Fêmea & $\begin{array}{l}\text { Diagnóstico realizado em 2008. Edema moderado nos dois } \\
\text { membros pélvicos. Permanece na propriedade. }\end{array}$ \\
\hline $907^{a}$ & Outubro 2006 & Fêmea & $\begin{array}{l}\text { Diagnóstico realizado em 2008. Edema moderado nos dois } \\
\text { membros pélvicos. Permanece na propriedade. }\end{array}$ \\
\hline $268^{a}$ & Outubro 2007 & Fêmea & $\begin{array}{l}\text { Diagnóstico realizado em } 2008 \text {. Edema acentuado no mem- } \\
\text { bro pélvico esquerdo. Permanece na propriedade. }\end{array}$ \\
\hline $346^{b}$ & Outubro 2007 & Macho & $\begin{array}{l}\text { Diagnóstico realizado em 2008. Edema acentuado nos mem- } \\
\text { bros pélvicos, cauda, região ventral do abdômen, tórax e } \\
\text { mandíbula. Bovino mais afetado do lote. }\end{array}$ \\
\hline $349^{a, c}$ & Outubro 2007 & Macho & $\begin{array}{l}\text { Diagnóstico realizado em 2008. Edema acentuado no mem- } \\
\text { bro pélvico esquerdo e moderado edema submandibular. }\end{array}$ \\
\hline $413^{a}$ & Outubro 2007 & Fêmea & $\begin{array}{l}\text { Diagnóstico realizado em } 2008 \text {. Edema acentuado no mem- } \\
\text { bro pélvico esquerdo e moderado no membro pélvico di- } \\
\text { reito. Permanece na propriedade. }\end{array}$ \\
\hline $545^{a}$ & Novembro 2007 & Macho & $\begin{array}{l}\text { Diagnóstico realizado em } 2008 \text {. Edema acentuado no mem- } \\
\text { bro pélvico direito. Permanece na propriedade. }\end{array}$ \\
\hline $948^{a, c}$ & Dezembro 2007 & Fêmea & $\begin{array}{l}\text { Diagnóstico realizado em } 2008 \text {. Edema acentuado no mem- } \\
\text { bro pélvico direito e moderado no membro pélvico esquerdo. }\end{array}$ \\
\hline $131^{a}$ & Outubro 2008 & Fêmea & $\begin{array}{l}\text { Diagnóstico realizado em 2009. Edema acentuado nos mem- } \\
\text { membros pélvicos. Mantido em potreiro no campus da Uni- } \\
\text { versidade Federal de Santa Maria. }\end{array}$ \\
\hline $393^{a, c}$ & Outubro 2008 & Macho & $\begin{array}{l}\text { Diagnóstico realizado em } 2009 \text {. Edema acentuado nos mem- } \\
\text { bros pélvicos, da cauda, do prepúcio, do escroto e da re- } \\
\text { gião abdominal ventral. }\end{array}$ \\
\hline 320 & Outubro 2008 & Fêmea & $\begin{array}{l}\text { Diagnóstico realizado em 2009. Edema moderado no mem- } \\
\text { bro pélvico direito. Permanece na propriedade. }\end{array}$ \\
\hline 250 & Novembro 2008 & Macho & $\begin{array}{l}\text { Diagnóstico realizado em 2009. Edema moderado no mem- } \\
\text { bro pélvico direito. Permanece na propriedade. }\end{array}$ \\
\hline
\end{tabular}

a O DNA desses bovinos foi testado contra o DNA do touro suspeito (Touro 1) e foi demonstrado que todos eles são filhos desse touro; ${ }^{b}$ morreu de causas não relacionadas em outubro de 2008 e não foi necropsiado; ${ }^{c}$ necropsiado após eutanásia. 
Quadro 2. Material colhido para a histopatologia dos bovinos afetados por linfedema primário congênito

\begin{tabular}{cl}
\hline Bovino & \multicolumn{1}{c}{ Órgãos coletados } \\
\hline 393 & $\begin{array}{l}\text { Linfonodos; ilíaco interno, íleo-femoral, inguinal superficial, retrofaríngeo, parotídeo, jejunal } \\
\text { axilar, subescapular, poplíteo direito e esquerdo.Baço, Rim, fígado, músculo esquelético, pe- } \\
\text { le da cauda, pele do dorso, encéfalo, rete mirabile carotídea. }\end{array}$ \\
349 & $\begin{array}{l}\text { Linfonodos; ilíaco interno, íleo-femoral, retrofaríngeo, jejunal, pré-escapular e poplíteo direito } \\
\text { e esquerdo. Bacio, rim, bexiga, fígado, pele da orelha e dos membros pélvicos, encéfalo, } \\
\text { rete mirabile carotídea. }\end{array}$ \\
$\begin{array}{l}\text { Linfonodos; ilíaco interno, íleo-femoral, retrofaríngeo, jejunal, axilar, pré-escapular, sub- } \\
\text { escapular, renal.Baço, rim, fígado, pele do membro posterior. }\end{array}$
\end{tabular}

analisados são internacionalmente recomendados pela ISAG (International Society of Animal Genetics) e os genótipos foram identificados pela deteç̧ão automatizada por eletroforese de capilar (Sequenciador Mega Bace) ${ }^{5}$.

Três bovinos afetados (Bov. 249, 393 e 948) e um controle normal (não relacionado à propriedade onde ocorreram os casos), foram necropsiados e vários órgãos foram colhidos para histopatologia (Quadro 2). Para observação dos vasos linfáticos, uma solução a $5 \%$ do corante azul de metileno foi injetada no espaço interdigital dos membros posteriores do controle e dos três terneiros necropsiados, duas horas antes da eutanásia.

\section{RESULTADOS}

A propriedade com o problema está localizada em município da região central do Rio Grande do Sul. Em abril de 2008 foi identificada nessa propriedade, uma doença que afeta bovinos cruza Red Angus ao nascimento. O período de inseminação na propriedade é de início de dezembro a início de abril do ano seguinte e cerca de 600 vacas são inseminadas por ano. Em 2005/2006 foi introduzido o sêmen de um novo touro Red Angus puro de pedigree (Touro 1) fornecido congelado por uma central de inseminação. No entanto, o proprietário não pôde precisar quantas das 600 vacas foram inseminadas com o sêmen desse touro naquela ocasião. O mesmo sêmen foi usado novamente nas três próximas estações de monta. Em 2006/2007 e 2007/2008 quase a totalidade das vacas foram inseminadas com o sêmen do Touro 1 e em 2008/ 2009 apenas as vacas ( 3 anos de idade e acima) foram inseminadas com o sêmen do desse touro, enquanto as novilhas (ao redor de 2 anos de idade) foram inseminadas com sêmen de outro touro da mesma raça.

Em abril de 2008 foram diagnosticados oito bovinos (Bovinos 268, 346, 349, 413, 530, 545, 948 e 907) afetados por linfedema (Quadro 1). Os terneiros nasciam afetados por edema, principalmente nos membros pélvicos (Fig.1), mas o edema ocorria ocasionalmente também em outras regiões do corpo (Quadro 1). Fissuras e rachaduras ocorriam na pele sobre as articulações de maior atrito.

Duas novilhas nascidas em outubro de 2006 (Bov. 530 e 907) foram confirmadas por palpação retal como prenhes em maio de 2008. No entanto, essas duas novilhas não haviam sido inseminadas com sêmen do Touro 1, e estavam prenhes de algum dos 11 touros Red Angus usa-

\footnotetext{
${ }^{5}$ Os testes de DNA foram realizados pelo Instituto H. Pardini, Rua Maranhão 1040, Belo Horizonte, MG 30150-3330. www.hermespardini.com.br
}

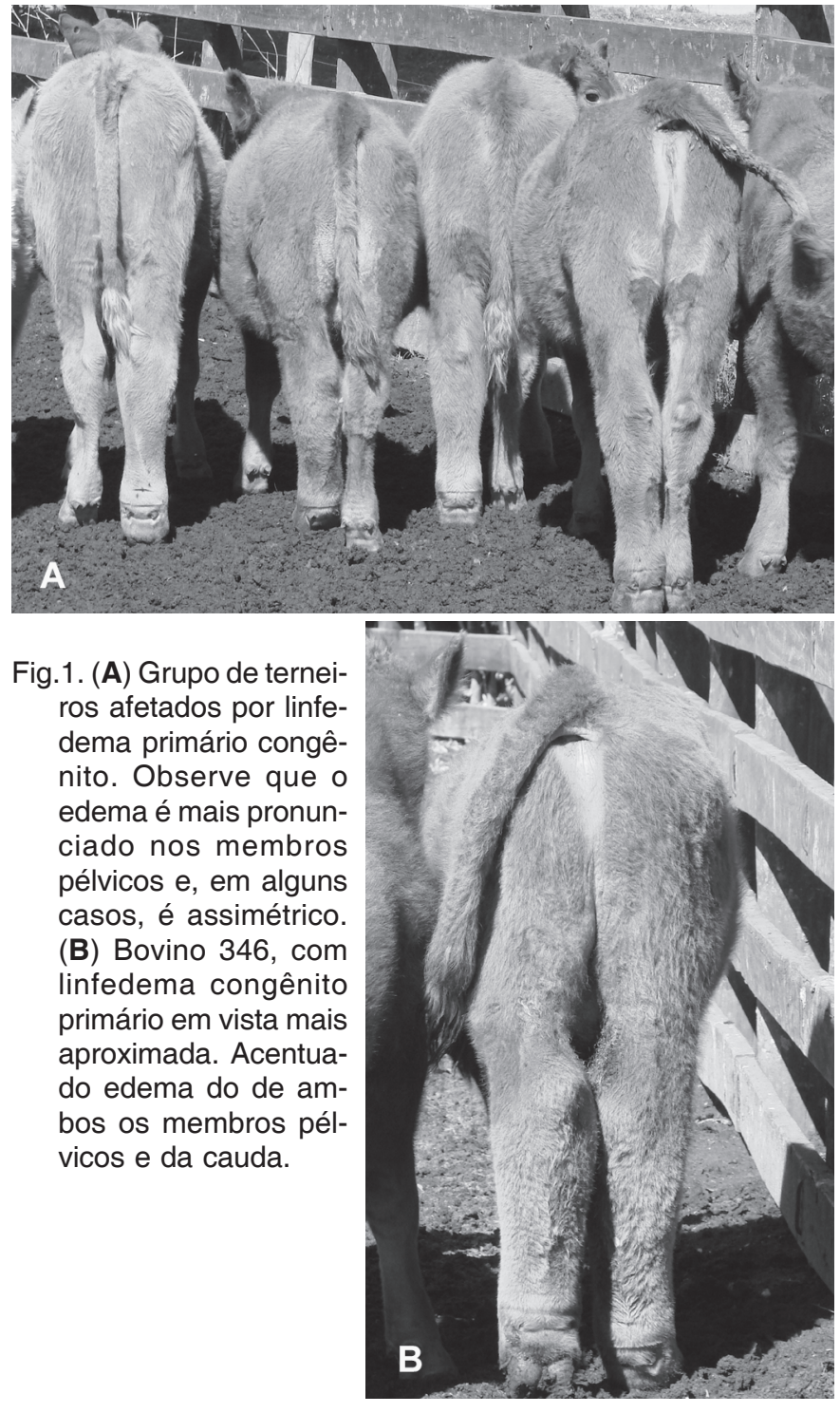

dos no repasse (para vacas que retornassem ao cio após a inseminação).

Na parição de 2009 nasceram, de vacas aparentemente normais, mais quatro terneiros afetados (Bov. 131, 250, 320 e 393). Os filhos das duas novilhas (Bov. 530 e 907), nasceram normais. O Bovino 346, um dos terneiros afetados nascidos em 2007, morreu de causas não relacionadas em outubro de 2008 e não foi necropsiado. Os ou- 
tros terneiros e as duas novilhas (Bov. 131, 250, 268, 320, $413,530,545$ e 907 ) permaneciam com edema quando examinados em abril de 2009, mas em outros aspectos eram aparentemente normais.

Numa outra propriedade investigada na região, e que usa o mesmo touro para inseminação, não foram observados casos. No entanto, nessa propriedade, o administrador informou que não havia possibilidade de cruzamento do Touro $1 \mathrm{com}$ as filhas desse touro.

Os resultados dos hemogramas e proteinogramas realizados em 2008 não demonstraram alterações. Nos

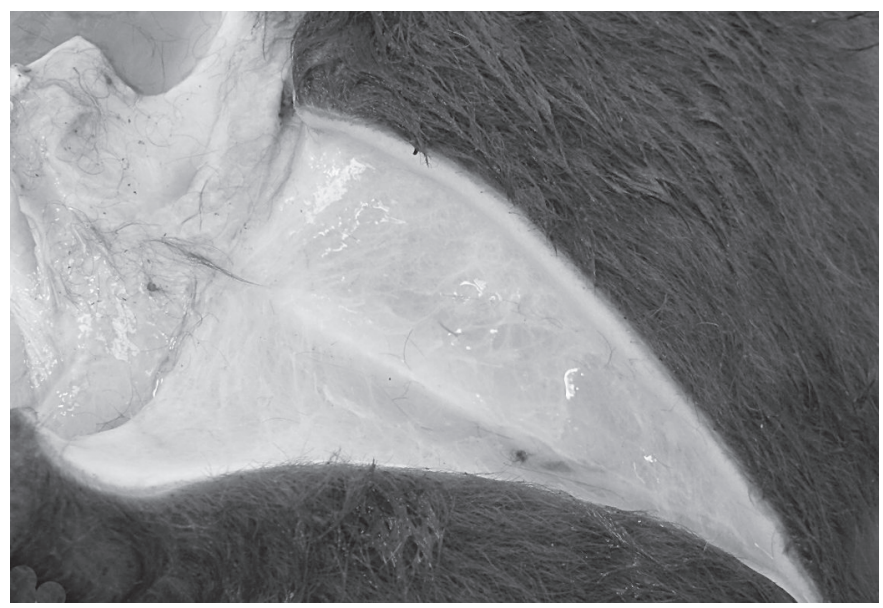

Fig.2. Aspecto translúcido e gelatinoso do tecido subcutâneo do bovino 393 afetado por linfedema primário congênito. A pele é espessa.

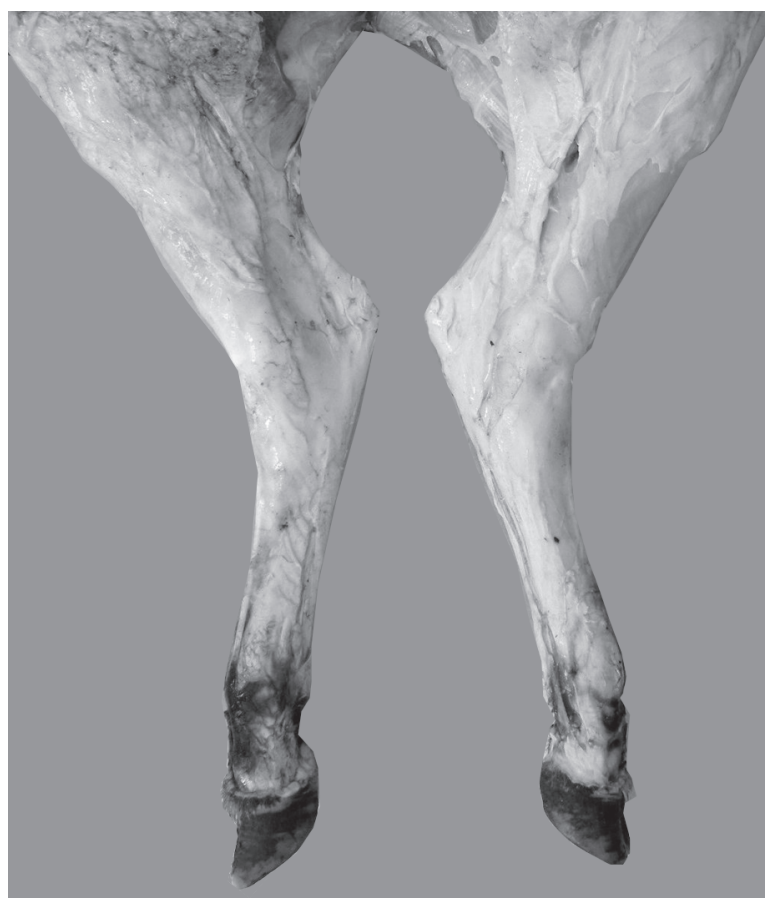

Fig.3. Aspecto do fluxo do corante azul de metileno duas horas após injeção interdigital nos dois membros pélvicos do Bovino 948, afetado por linfedema primário congênito. O corante ficou restrito às porções proximais dos dois membros. mesmos exames, repetidos, em 2009, os Bovinos 131, 349 e 948 tiveram respectivamente hemogramas $22,3 \%$, $21,8 \%$ e $18,6 \%$ demonstrando um grau moderado de anemia (referência: $24 \%-46 \%$, média $34 \%$ ).

Os testes de paternidade demonstraram que o Touro 1 é pai de todos os bovinos afetados por linfedema que foram testados (Quadro 1)

$\mathrm{Na}$ necropsia, as regiões do corpo afetadas por edema mostravam espessamento do tecido subcutâneo por material de aspecto translúcido e gelatinoso que era recoberto por ele espessada (Fig.2). Nos animais que tinham a lesão por mais tempo (Bov. 349 e 948) o edema era associado à fibrose. No Bovino 349 , a distribuição do edema envolvia o membro pélvico esquerdo, principalmente abaixo do jarrete, o prepúcio e a região abdominal ventral. No Bovino 948 o edema subcutâneo se restringia aos membros pélvicos, principalmente abaixo do jarrete e no Bovino 393 envolvia o subcutâneo dos membros pélvicos, da cauda, do prepúcio, do escroto e da região abdominal ventral até o externo. $\mathrm{O}$ azul de metileno injetado entre os entre os dígitos dos membros pélvicos ficava diluído no edema subcutâneo da extremidade distal do membro afetado, sugerindo que o corante não era drenado em razão da vasculatura linfática ser incompleta, sem conexão entre as partes proximais e distais. Isso ocorria de forma bilateral nos Bovinos 393 e 948 (Fig.3), mas ocorria apenas no membro pélvico direito no Bovino 349 , em que o corante era drenado normalmente no membro pélvico esquerdo não afetado por edema (Fig.4); nesse bovino, o linfonodo poplíteo esquerdo era acentuadamente menor que seu correspondente direito (Fig.5). A drenagem linfática do corante ocorreu normalmente no bovino controle. Fissuras na pele que recobre as articulações eram evidentes nos três bovinos com linfedema necrop-

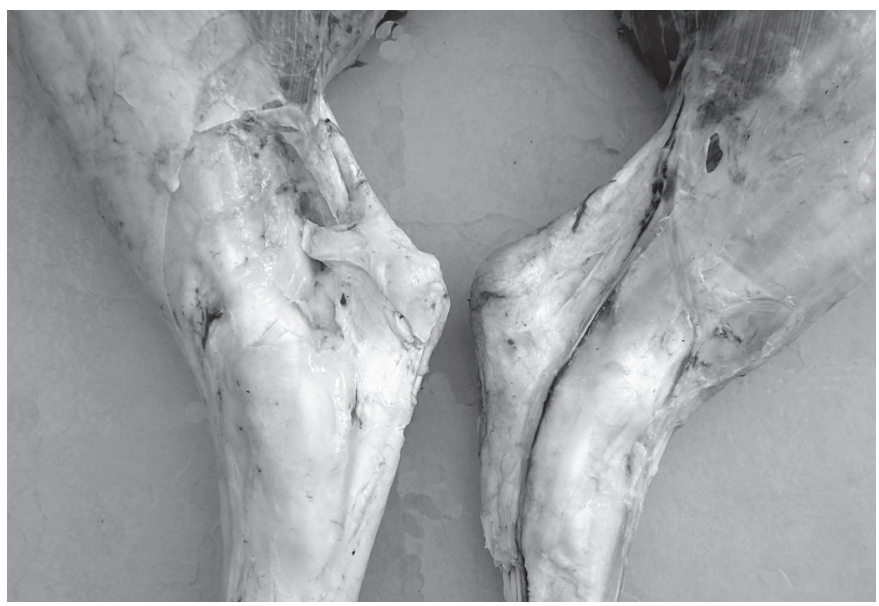

Fig.4. Aspecto do fluxo do corante azul de metileno duas horas após injeção interdigital nos dois membros pélvicos do Bovino 349. Observe que no membro pélvico direito há um vaso repleto do corante drenado, portanto, normalmente (esse membro não era afetado por edema). No membro pélvico esquerdo (afetado por edema) não se observa drenagem do corante. 




Fig.5. Linfonodos poplíteos do Bovino 349. Observe que o linfonodo poplíteo a esquerda (membro afetado pelo edema) é acentuadamente menor que o linfonodo correspondente direito, indicando hipoplasia do linfonodo que drena o membro afetado. Adicionalmente a cor azulada do linfonodo normal indica que o corante drenou até o linfonodo duas horas após sua injeção no espaço interdigital, o que não ocorreu no caso do linfonodo hipoplásico.

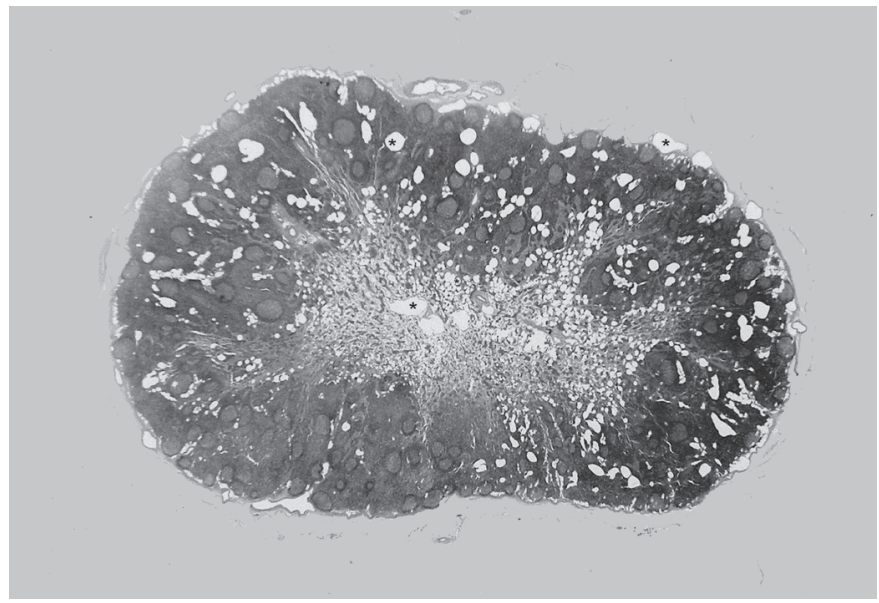

Fig.6. Linfonodo poplíteo do Bovino 948 com hipoplasia e acentuada distensão dos vasos e seios linfáticos (asteriscos). HE, obj.2,5x.

siados. Alterações encontradas ao exame histológico incluíam hipoplasia dos linfonodos poplíteos com acentuada distensão dos vasos linfáticos nesses linfonodos (Fig.6). Essas lesões eram unilaterais no Bovino 349 e bilaterais no Bovino 948.

\section{DISCUSSÃO}

O diagnóstico de linfedema baseou-se nos aspectos clínicos e patológicos. Na doença observada aqui, o edema estava presente ao nascimento. A distribuição do edema era caracteristicamente localizada no tecido subcutâneo dos membros, principalmente nos membros pélvicos. Como uma regra geral, a maiorias das condições patológicas que resultam em edema em ruminantes causam edema das partes de declive do animal, isto é, tecido sub- cutâneo da barbela, partes ventrais do tórax e do abdômen. Os quatro mecanismos principais de edema incluem lesões cardíacas, hepáticas, aumento da permeabilidade vascular e obstrução hepática (Mitchell 1999, Mosier 2007). A distribuição do edema nesses casos, considerada pouco comum (Morris et al. 1954), combinada ao fato de que os terneiros afetados apresentavam outros sinais clínicos essencialmente normais, tendem a excluir outras causas de edema como insuficiência cardíaca, insuficiência hepática ou edema inflamatório. Tendo-se excluído as outras causas de edema, um diagnóstico clínico de linfedema primário foi estabelecido. Linfedema primário é uma síndrome caracterizada pela formação de edema que ocorre devido a defeitos dos vasos linfáticos ou linfonodos (Kinmonth 1965, Davies et al. 1979). Essas alterações foram encontradas nos terneiros deste estudo e uma causa hereditária é aparente como tem sido os casos de linfedema primário descritos em pessoas (Esterly 1965, Kinmonth 1965, Singh et al. 1966, Olszewski et al. 1972) bovinos (Donald et al. 1952, Morris et al. 1954, Schild et al. 1982, Carapeto 1984, Schild et al. 1991,1996), cães (Luginbühl et al. 1967, Patterson et al. 1967, Davies et al.1979, Leighton \& Suter 1979, Carmichael et al. 1986) e suínos (Van der Putte et al. 1978, Maxie \& Robinson 2007).

Testes de DNA confirmaram que o touro usado na inseminação das vacas, é pai dos terneiros afetados pelo linfedema. A julgar pelo baixo número (12) de terneiros afetados, a condição deve ser autossômica recessiva como é o caso do linfedema em bovinos Ayrshire (Donald et al. 1952, Morris et al. 1954), uma vez que ao redor de 600 vacas são inseminadas com o sêmen do touro portador do gene causador da doença. É interessante notar que o sêmen do Touro 1 , sendo comercialmente muito procurado, deve ter sido usado em várias outras propriedades sem que houvessem queixas de casos de linfedema. O aparecimento da doença na propriedade relatada aqui deve ter sido facilitada pelo fato de novilhas filhas do Touro 1 terem sido inseminadas com seu sêmen. Isso está em acordo com o modo transmissão hereditária autossômica recessiva. Caso a doença fosse autossômica dominante, como é o caso dos bovinos Hereford (Schild et al. 1982, Carapeto 1984, Schild et al. 1991,1996), seria esperado que o touro imprimisse a doença em aproximadamente metade das vacas inseminadas. Estudos complementares estão sendo iniciados para definir com certeza o caráter autossômico recessivo da condição descrita aqui.

Morfologicamente a principal alteração da doença parece ser a falta de desenvolvimento (aplasia) ou desenvolvimento incompleto (hipoplasia) dos vasos linfáticos. Uma repercussão moderada nos linfonodos poplíteo (hipoplasia) foi também observada. Essas alterações resultam em edema, localizado principalmente nos membros pélvicos. No entanto, ao contrário do que é descrito em outros relatos (Schild et al. 1991), as lesões nos linfonodos nos nossos casos são leves e parecem não ser 
fundamentais para o desenvolvimento do edema, pois a lesão ocorreu em um animal sem evidência de aplasia/ hiperplasia de linfonodos. Nestes casos, o defeito parece ser relacionado à falta de conexão entre as porções proximais e distais da circulação linfática, de modo semeIhante ao que é descrito para o, linfedema primário congênito hereditário em cães (Patterson et al. 1967, Luginbühl et al. 1967).

\section{REFERÊNCIAS}

Carapeto L.P. 1984. Estudo radiológico de hipoplasia linfática hereditária em bovinos Hereford. Dissertação de Mestrado, Universidade Federal de Pelotas, Pelotas, RS. 37p.

Carmichael N.G., Watson A.D.J. \& Rothwell T.L.W. 1986. Secondary lymphoedema in a dog. J. Small Anim. Pract. 27:335-341.

Davies A.P., Hardy R., Larsen R., Lees G.E. \& Hayden D.W. 1979. Primary lymphoedema in three dogs. J. Am. Vet. Med. Assoc. 174:1316-1320.

Donald H.P., Deas D.W. \& Wilson A.L. 1952. Genetical analysis of the incidence of dropsical calves in herds of Ayrshire cattle. Brit. Vet. J. 108:227-245.

Esterly J.R. 1965. Congenital hereditary lymphoedema. J. Med. Genet. 2:93-98.

Kinmonth S.B. 1965. Lymphoedema of the lower limb. Proc. R. Sot. Med. 58:1021-1023.

Leighton R.L. \& Suter P.F. 1979. Primary lymphedema of the hindlimb in the dog. J. Am. Vet. Med. Assoc. 175:369-374.

Luginbühl H., Chacko S.K., Patterson D.F. \& Medway W. 1967. Congenital hereditary lymphoedema in the dog. Part II. Pathological studies. J. Med. Genet.4:153-165.

Maxie M.G. \& Robinson W.S.F. 2007. Cardiovascular system, p.1-105. In. Maxie M.G. (Ed.), Jubb, Kennedy, and Palmer's Pathology of Domestic Animals. Vol.3. 5th ed. Saunders Elsevier, Philadelphia. $737 p$.
Mitchell R.N.. 1999. Hemodynamic disorders, thromboemboic disease, and shock, p.119-144. In: Kumar V., Abbas A.K. \& Fausto N. (Eds), Robbins and Cotran's Pathologic Basis of Disease. 7th ed. Elsevier Saunders, Philadelphia. 1525p.

Morris B., Blood D.C., Sidman W.R., Steel J.D. \& Whittem J.H. 1954 Congenital lymphatic oedema in Ayrshire calves. Aust J. Exp. Biol. Med. Sci. 32:265-274.

Mosier D.A. 2007. Vascular disorders and thombrosis, p.63-99. In: McGavin M.D. \& Zachary J.F. (Eds), Pathologic Basis of Veterinary Disease. 4th ed. Mosby Elsevier, St Louis. 1476p.

Olszewski W., Machowski Z., Sokolowski J., Sawicki Z., Zerbino D. \& Nielubowicz J. 1972. Primary lymphedema of lower extremities. I. Lymphangiographic and histological studies of lymphatic vessels and lymph nodes in primary lymphedema. Pol. Med. J. 11:1564-1572.

Patterson D.F., Medway W., Luginbühl H. \& Chacko S. 1967. Congenital hereditary lymphoedema in the dog. Part I. Clinical and genetic studies. J. Med. Genet. 4:145-152.

Schild A.L., Carapeto L.P., Riet-Correa F., Méndez M.C. \& Guerreiro G. 1996. Radiological study of hereditary lymphedema in hereford cattle. Pesq. Vet. Bras. 16:21-26.

Schild A.L., Riet-Correa F. \& Méndez M.C. 1991. Hereditary lymphedema in Hereford cattle. J. Vet. Diagn. Invest. 3:47-51.

Schild A.L., Riet-Correa F., Méndez M.C. \& Oliveira J.A. 1982. Hipoplasia linfática congenita em bovinos Hereford. 18을 Congresso Brasileiro de Medicina Veterinária, Camboriu, Santa Catarina, p.21. (Resumo)

Schoen F.J. 2005. Blood vessels, p.511-554. In: Kumar V., Abbas A.K. \& Fausto N. (Eds), Robbins and Cotran's Pathologic Basis of Disease. 7th ed. Elsevier Saunders, Philadelphia. 1525p.

Singh S.D., Yesikar S.S., Aziz S. \& Munjal S. 1966. Congenital lymphoedema: Report of a case with brief review of the literature. Indian J. Pediatr. 33:47-49.

Van der Putte S.C.J. 1978. The Pathogenesis of congenital hereditary lymphedema in the pig. Lymphology 11:10-21.

Yamaguchi R., Amos J.M., Hagio M. \& Tateyama S. 1995. Congenital lymphedema in a calf with lymh node dysplasia or aplasia. J. Vet. Med. Sci. 57:797-799. 